
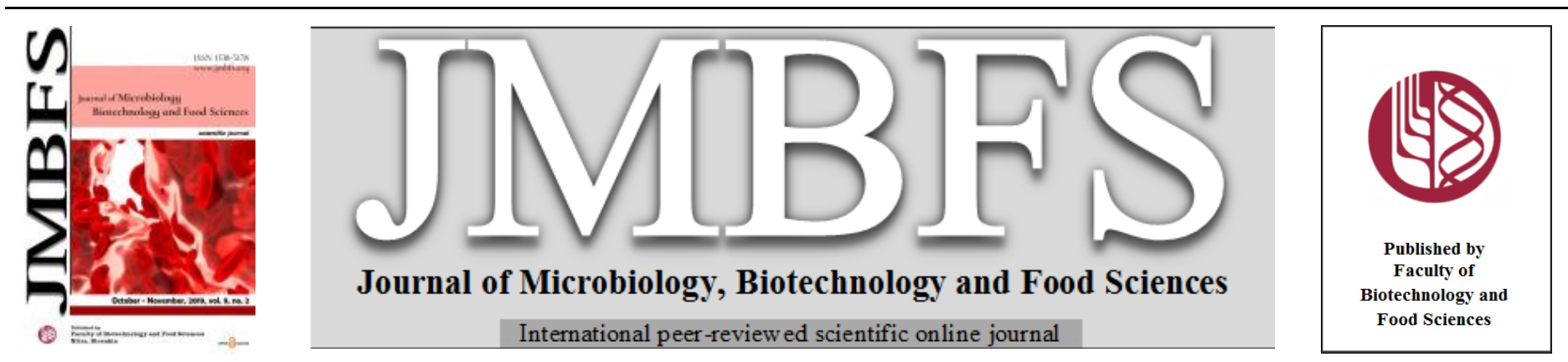

\title{
METAGENOMICS IN-SIGHT INTO THE MICROBIAL STRUCTURAL DIVERSITY OF ANAEROBIC DIGESTER UTILISING FRUIT WASTE AS SUBSTRATE
}

\author{
Anika Ogemdi Chinwendu ${ }^{* 1,2}$, Akin-Osanaiye Bukola Catherine ${ }^{2}$, Edet Uwem Okon ${ }^{1,3}$ \\ Address(es): \\ ${ }^{1}$ University of Calabar, Faculty of Biological Sciences, Department of Microbiology, PMB 1115 Calabar-Nigeria. \\ ${ }^{2}$ University of Abuja, Abuja, Faculty of Sciences, Department of Microbiology, PMB117, Abuja-Nigeria. \\ ${ }^{3}$ Obong University, Faculty of Natural and Applied Sciences, Obong Ntak, Etim Ekpo, Akwa Ibom-Nigeria.
}

*Corresponding author: ogemdianika@yahoo.com

doi: 10.15414/jmbfs.2020.9.5.965-969

ARTICLE INFO

Received 17. 5. 2019

Revised 15. 11. 2019

Accepted 19. 11. 2019

Published 1. 4. 2020

\section{Regular article \\ open $\partial_{\text {ACCESS }}$}

\begin{abstract}
Anaerobic digester has emerged as a technology of choice in management of waste and production of biogas. However, the microbial ecology of digesters utilizing various substrates are very poorly understood. The ecology of anaerobic digester utilizing Citrullus lanatus fruit waste was analyzed using metagenomics. Slurry substrate sample was collected from a functional digester aseptically and anaerobically. Metagenomic DNA was extracted using ZYMO DNA extraction Kit (Model D 6001, Zymo Research, USA) following manufacturer's instruction. Extracted DNA was amplified using the 16S rRNA gene amplicon PCR primers set and sequenced using Illumina MiSeq platform. Taxonomic analysis of the reads was performed using NCBI-BLAST-2.2.24 and CLC bio Genomics workbench v7.5.1. Taxonomic classification of the sequences revealed that bacteria and archae were the top two kingdoms with reads counts of 57,554 and 80, respectively. The top 7 phyla were Unknown, Firmicutes, Proteobacteria, Planctomycetes, Bacteroidetes, Actinobacteria and Euryarchaeota in decreasing order of counts. A total of 30 microbial classes, 43 orders, 79 families and 210 species were further classified. Over half of the 210 species detected were not routinely cultured species in the laboratory, indicating that there is still a relatively wide gap between culturable and non-culturable species in an anaerobic digester. The Acidogens captured in this study were Clostridium, Uncultured rumen bacteria and Bacteroidetes species. Furthermore, we also detected uncultured syntrophic Acetogens such as Syntrophomonas species and the hydrogenotrophic thermophile, Methanothermobacter sp. The Syntrophomonas species is known to breakdown short chain fatty acids, like propionate and butanoate in concert with hydrogenotrophic Methanogens indicating methane generation was via the hydrogenotrophic route. However, the main representative hydrogenotrophic methanogens detected were Methanoculleus bourgensis and Methanoculleus marisnigri, with the former being more abundant. In addition to the aforementioned species, other species captured were largely classified as unknown or uncultured species and they include Uncultured species of Clostridium, Syntrophomonas, Synergistetes, Synergistaceae Anaerobic sp, Ruminococcaceae, Rumen sp, Thermomonas, Thermoanaerobacteriales, Bacterium, Compost, Firmicutes, Bacteroidetes, Chloroflexi, Clostriaceae, Acetobacter. Eubacterium, Alpha and Aacteroides. The results of the study revealed that culture-independent approach is better able to capture the anaerobes including both culturable and unknown that dominate anaerobic digesters and are responsible for the bioconversion of organic waste into biogas.
\end{abstract}

\section{INTRODUCTION}

With increasing awareness of the health benefits of fruits, there has been an increased cultivation and consumption of fruits around the world (Ijah et al., 2015; Sagar et al., 2018). In most developing countries such as Nigeria, fruit waste disposal is usually not properly handled despite enormous potentials (Oladepo et al., 2015; Sagar et al., 2018). Furthermore, the lack of post-harvest technology or preservation techniques for fruits increases the quantity of wastes generated from fruits in Nigeria. Anaerobic degradation of waste is a well-known method of biological waste treatment with concomitant production of biogas such as methane and carbon dioxide using a complex community of microorganisms (Kleinsteuber, 2018).

The processes of anaerobic biogas generation are divided into four major stages namely: hydrolysis, acidogenesis, acetogenesis and methanogenesis (Sagagi $\boldsymbol{e t}$ al., 2009). During hydrolysis, complex organic polymers are broken down into simpler forms (Cirne et al., 2007; Doi, 2008). If the substrate is not readily degradable, this phase may limit the entire process (Parawira, 2005). However, if the substrate is easily digested, then methanogenesis would be the phase that may limit the process in the reactor (Bjornsson, 2001). The process of acidogenesis involves further disintegration of the components into compounds such as organic acids, ketones, alcohols and carbon dioxide (Ding $\boldsymbol{e t}$ al., 2008). Meanwhile, the resulting acidogenic products are converted into hydrogen, carbon dioxide and acetic acid during acetogenesis (Schink, 1997). In the methanogenic stage, the acetogenic products are transformed into methane and $\mathrm{CO}_{2}$ which make up the bulk of the biogas liberated from the process (Verma $e t$ al., 2007).

Anaerobic digestion (AD) is a very complex biological process. Despite being so widely used around the world, the microbial ecology of this process is very poorly understood (Nelson et al., 2010; Amha et al., 2018). Unfolding and proper understanding of the complex structural diversity is very important in understanding functional relationship between the various metabolic groups of microorganisms (hydrolytic, acidogenic, acetogenic and methanogenic) Understanding this synergy will help improve and optimize the process of $A D$ thereby making it more effective (Manyi-Loh et al., 2013; Amha et al., 2018).

Most of the microorganisms involved in $\mathrm{AD}$ are anaerobes and their cultivation in the laboratory is one of the most challenging areas of microbial research (Mori and Kamagata, 2014). Before the advent of molecular tools such as metagenomics, microbial ecology of various environments including those of the anaerobic world were largely elusive (Edet et al., 2017a; Edet et al., 2017b; Edet et al., 2018a; Edet et al., 2018b; Mori and Kamagata, 2014) Metagenomics, a culture-independent method allows for the direct examination of microbial community structure and function in an ecosystem using various bioinformatics pipelines (Edet et al., 2017a; Manyi-Loh et al., 2013). Application of omics-based studies have revealed a number of things previously unknown to the anaerobic microbial world such as new taxa and their roles in 
various anaerobic systems (Manyi-Loh et al., 2013; Mori and Kamagata, 2014).

Microbial composition in an anaerobic digester is driven by a number of factors Prominent amongst the factors is the type of substrate utilized in the AD and free ammonia (Zhang et al., 2014; Li et al., 2015). Other factors include design of the reactor and its operational condition such as hydraulic retention time, organic loading rates $\mathrm{pH}$, temperature and mixing (Lin et al., 2013; Town et al., 2014; Manyi-Loh et al., 2013) and even co-substrate (Sun et al., 2015). In Nigeria, a number of studies abound on the utilization of anaerobic digestion systems in biogas production and waste treatment but none have utilized metagenomics in the evaluation of microbial structure. Thus, the primary aim of this study was characterization of the microbial communities in an anaerobic digester utilizing water melon fruit waste in biogas production process

\section{MATERIAL AND METHODS}

\section{Sampling of slurry}

Slurry sample from an operational digester was collected for characterization of the microbial community composition of the digesters after shaking to achieve a uniform mixture. The samples from the digester were collected from the outlet tap using a sterile capped bottle and transported immediately for immediate analysis. The operational conditions of the digester have been described previously (Anika et al., 2019).

\section{Metagenomic DNA extraction}

DNA extraction from slurry sample was performed using ZYMO DNA extraction Kit (Model D 6001, Zymo Research, USA) adhering to the manufacturer's instructions.

\section{DNA amplification and electrophoresis}

The universal bacterial 16S rRNA gene amplicon PCR primers set TruSeq tailed 341F

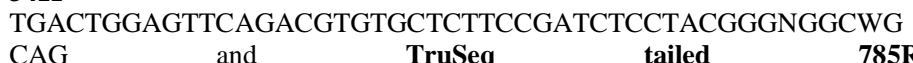
ACACTCTTTCCCCACACGACGCTCTTCCGATCTGACTACHVGGGTATC

TAATCC was used to amplify and produce more copies of target region in the extracted metagenome. The reactants (substrates) for DNA amplification were prepared using $2.5 \mu \mathrm{L}(5 \mathrm{ng} / \mu \mathrm{L})$ microbial DNA, $5 \mu \mathrm{L}(1 \mu \mathrm{M})$ amplicon PCR forward primer, $5 \mu \mathrm{L}(1 \mu \mathrm{M})$ amplicon PCR reverse primer, and $2 \times \mathrm{KAPA} H i F i$ Hot Start Ready Mix $12.5 \mu \mathrm{L}$ (total $25 \mu \mathrm{L}$ ). Using the reaction mixture above, the following protocol was used to run a PCR for the slurry extracted DNAs in a thermal cycler (Applied Biosystems9700, USA) for twenty five cycles: The firs cycle was allowed to denature for three minutes at $95{ }^{\circ} \mathrm{C}$, but for the rest cycles that followed, the DNAs were denatured for five minutes at $95{ }^{\circ} \mathrm{C}$. Following, the temperature of the reaction mixture was brought down to $55^{\circ} \mathrm{C}$ for three minutes to allow for DNA annealing and later increased to $72{ }^{\circ} \mathrm{C}$ for thirty seconds for elongation to take place, then, another five minutes was allowed at same temperature for a final extension. Exactly $1 \mu \mathrm{L}$ was run on a bioanalyzer DNA 1000 chip to verify the size of the amplified product (approximately 550bp)

\section{Illumina sequencing}

In order to assess all the nucleotide sequences present in the DNAs eluted from digesting slurry samples (to reveal all the microbial communities present), DNA sequencing was carried out using Next Generation Sequencing Technique, following library preparation, using automated PCR cycle- Genome Sequencer ${ }^{\mathrm{TM}}$ MiSeq (Illumina). Vecton NTI suite 9 (InforMax, Inc.) was used to analyze and align the sequences (Salam et al., 2017; Edet et al., 2017a).

\section{Taxonomic analysis}

Following next generation sequencing, quality control and trimming of the sequences was performed as reported previously (Salam $\boldsymbol{e t}$ al., 2017; Edet $\boldsymbol{e t}$ al., 2017a). Taxonomic analysis of the reads was performed using NCBI-BLAST2.2.24 and CLC bio Genomics workbench v7.5.1 (Edet et al., 2017a).

\section{RESULTS}

The results of the study are presented in the tables below. Table 1 shows the various kingdom in our studied sample. The various kingdoms classified were Bacteria, Archae, Unknown, Fungi, Plantae, Animalia, and Protozoa in decreasing order of abundance. Their read counts were 57554, 80, 23, 7, 4, 3, and 2 , respectively. As can be seen from the read counts, bacteria were the most dominant kingdom representing $99.79 \%$ and the followed by archae with $0.14 \%$. Unknown kingdom represented $0.04 \%$ while fungi, plantae, and animalia represented $0.01 \%$ each. The least abundant kingdom was protozoa with a representation that was less than $0.00 \%$.
Phylum classification revealed a total of 18 phyla with various read counts as shown in Table 2. These were Unknown, Firmicutes, Proteobacteria, Planctomycetes, Bacteroidetes, Actinobacteria, Euryarchaeota, Chloroflexi, Lentisphaerae, Ascomycota, Basidiomycetes, Chordata, Tracheophyta Ciliophora, Cyanobacteria, Deinococcus-Thermus, Bryophyta, and Crenarchaeota with reads of 53739, 2206, 1177, 186, 186, 116,84, 79, 59, 8, 4, 3, $3,2,1,1,1,1$ and 1 , respectively.

Class classification as presented in table 3, revealed a total of 30 classes including the Unknown and Not Assigned categories. The top 15 classes were Unknown, Clostridia, Gammaproteobacteria, Bacilli, Planctomycetacia, Alphaproteobacteria, Actinobacteria, Bacteroidetes, Chloroflexi, Betaproteobacteria, Halobacteria, Flavobacteria, Methanomicrobia Lentisphaerae, and Deltaproteobacteria. Their corresponding read counts were $53740,1792,1010,414,186,107,84,72,58,54,46,43,32,8$ and 6 .

A total of 43 orders were captured in our sample. The top 30 orders are as presented in Table 4. The top 15 orders were Unknown, Clostridiales, Clostridiales, Bacillales, Planctomycetales,

Planctomycetales, Xanthomonadales, Actinomycetales, Bacteroidales, Chloroflexales, Burkholderiales, Halobacteriales, Flavobacteriales, Methanomicrobiales and Rhodospirillales. Their corresponding read counts were 53748, 1792, 908, 401, 186, 401, 186, 85, 79, 72, 58, 54, 46 and 43. Also included in the top 30 orders was an important methanogen order, Methanomicrobiales.

The various families were 79 in total. However, the top 30 orders in our AD sample is presented in table 5. In increasing order of read counts, they were Unknown, Clostridiaceae, Enterobacteriaceae, Listeriaceae, Eubacteriaceae Planctomycetaceae, Xanthomonadaceae, Prevotellaceae, Halobacteriaceae, Flavobacteriaceae, Not assigned, Bacillaceae, Comamonadaceae Syntrophomonadaceae, Rhodobacteraceae, Dietziaceae, Acetobacteraceae, Rhodospirillaceae, Phyllobacteriaceae, Sphingomonadaceae, Burkholderiaceae, Pseudomonadaceae, Lactobacillaceae, Caulobacteraceae, Alcaligenaceae, Victivallaceae, Pseudonocardiaceae, Bradyrhizobiaceae, Nocardioidaceae and Micrococcaceae. Their respective read counts were 54160, 1060, 908, 365, 349, $186,85,69,46,43,35,30,30,36,23,21,16,15,13,12,12,10,10,10,9,8,7,7$ 7 and 7 . The remaining families are as captured in the supplementary material attached. In addition to the aforementioned families, Methanobacteriaceae and Methylobacteriaceae were also detected in our sample.

Genus/species level classification revealed a total of 210 species majority of which were uncultured species. Selected 45 species are as presented in Table 6 These were dominated by strict anaerobes or facultative anaerobes as well as methanogens and methane utilizing species.

Table 1 Kingdom classification

\begin{tabular}{lll}
\hline Kingdoms & Read counts & Percentage $(\boldsymbol{\%})$ \\
\hline Bacteria & 57554 & 99.79 \\
Archae & 80 & 0.14 \\
Unknown & 23 & 0.04 \\
Fungi & 7 & 0.01 \\
Plantae & 4 & 0.01 \\
Animalia & 3 & 0.01 \\
Protozoa & 2 & 0.00 \\
\hline
\end{tabular}

Table 2 Phyla classification

\begin{tabular}{lll} 
Phyla & Read count & \% \\
\hline Unknown & 53739 & 93.18 \\
Firmicutes & 2206 & 3.83 \\
Proteobacteria & 1177 & 2.04 \\
Planctomycetes & 186 & 0.32 \\
Bacteroidetes & 116 & 0.20 \\
Actinobacteria & 84 & 0.15 \\
Euryarchaeota & 79 & 0.14 \\
Chloroflexi & 59 & 0.10 \\
Lentisphaerae & 8 & 0.01 \\
Ascomycota & 4 & 0.01 \\
Basidiomycota & 3 & 0.01 \\
Chordata & 3 & 0.01 \\
Tracheophyta & 3 & 0.01 \\
Ciliophora & 2 & 0.00 \\
Cyanobacteria & 1 & 0.00 \\
Deinococcus-thermus & 1 & 0.00 \\
Bryophyta & 1 & 0.00 \\
Crenarchaeota & 1 & 0.00 \\
\hline
\end{tabular}


Table 3 Class classification

\begin{tabular}{lll}
\hline Class & Read Count & $\%$ \\
\hline Unknown & 53740 & 93.18 \\
Clostridia & 1792 & 3.11 \\
Gammaproteobacteria & 1010 & 1.75 \\
Bacilli & 414 & 0.72 \\
Planctomycetacia & 186 & 0.32 \\
Alphaproteobacteria & 107 & 0.19 \\
Actinobacteria & 84 & 0.15 \\
Bacteroidetes & 72 & 0.12 \\
Chloroflexi & 58 & 0.10 \\
Betaproteobacteria & 54 & 0.09 \\
Halobacteria & 46 & 0.08 \\
Flavobacteria & 43 & 0.07 \\
Methanomicrobia & 32 & 0.06 \\
Lentisphaerae & 8 & 0.01 \\
Deltaproteobacteria & 6 & 0.01 \\
Mammalia & 3 & 0.01 \\
Agaricomycetes & 2 & 0.00 \\
Saccharomycetes & 2 & 0.00 \\
Leotiomycetes & 2 & 0.00 \\
Heterotrichea & 2 & 0.00 \\
Bryopsida & 1 & 0.00 \\
Sphingobacteria & 1 & 0.00 \\
Lycopodiopsida & 1 & 0.00 \\
Anaerolineae & 1 & 0.00 \\
Methanobacteria & 1 & 0.00 \\
Not assigned & 1 & 0.00 \\
Thermoprotei & 1 & 0.00 \\
Polypodiopsida & 1 & 0.00 \\
Deinococci & 1 & 0.00 \\
Cycadopsida & 1 & 0.00 \\
\hline & &
\end{tabular}

Table 4 Top 30 orders

\begin{tabular}{lll}
\hline Order & Read Count & $\%$ \\
\hline Unknown & 53748 & 93.19 \\
Clostridiales & 1792 & 3.11 \\
Enterobacteriales & 908 & 1.57 \\
Bacillales & 401 & 0.70 \\
Planctomycetales & 186 & 0.32 \\
Xanthomonadales & 85 & 0.15 \\
Actinomycetales & 79 & 0.14 \\
Bacteroidales & 72 & 0.12 \\
Chloroflexales & 58 & 0.10 \\
Burkholderiales & 54 & 0.09 \\
Halobacteriales & 46 & 0.08 \\
Flavobacteriales & 43 & 0.07 \\
Methanomicrobiales & 32 & 0.06 \\
Rhodospirillales & 31 & 0.05 \\
Rhizobiales & 28 & 0.05 \\
Rhodobacterales & 23 & 0.04 \\
Lactobacillales & 13 & 0.02 \\
Sphingomonadales & 12 & 0.02 \\
Caulobacterales & 10 & 0.02 \\
Pseudomonadales & 10 & 0.02 \\
Victivallales & 8 & 0.01 \\
Myxococcales & 4 & 0.01 \\
Alteromonadales & 4 & 0.01 \\
Primates & 3 & 0.01 \\
Thelebolales & 2 & 0.00 \\
Agaricales & 2 & 0.00 \\
Saccharomycetales & 2 & 0.00 \\
Heterotrichida & & 0.00 \\
Chromatiales & & 0.00 \\
\hline & &
\end{tabular}

Table 5 Top 30 families

\begin{tabular}{lll}
\hline Family & Read Count & $\%$ \\
\hline Unknown & 54160 & 93.91 \\
Clostridiaceae & 1060 & 1.84 \\
Enterobacteriaceae & 908 & 1.57 \\
Listeriaceae & 365 & 0.63 \\
Eubacteriaceae & 349 & 0.61 \\
Planctomycetaceae & 186 & 0.32 \\
Xanthomonadaceae & 85 & 0.15 \\
Prevotellaceae & 69 & 0.12 \\
Halobacteriaceae & 46 & 0.08 \\
Flavobacteriaceae & 43 & 0.07 \\
Not assigned & 35 & 0.06 \\
Bacillaceae & 30 & 0.05 \\
Comamonadaceae & 30 & 0.05 \\
\hline
\end{tabular}

\begin{tabular}{lcc}
\hline Syntrophomonadaceae & 26 & 0.05 \\
Rhodobacteraceae & 23 & 0.04 \\
Dietziaceae & 21 & 0.04 \\
Acetobacteraceae & 16 & 0.03 \\
Rhodospirillaceae & 15 & 0.03 \\
Phyllobacteriaceae & 13 & 0.02 \\
Sphingomonadaceae & 12 & 0.02 \\
Burkholderiaceae & 12 & 0.02 \\
Pseudomonadaceae & 10 & 0.02 \\
Lactobacillaceae & 10 & 0.02 \\
Caulobacteraceae & 10 & 0.02 \\
Alcaligenaceae & 9 & 0.02 \\
Victivallaceae & 8 & 0.01 \\
Pseudonocardiaceae & 7 & 0.01 \\
Bradyrhizobiaceae & 7 & 0.01 \\
Nocardioidaceae & 7 & 0.01 \\
Micrococcaceae & 7 & 0.01 \\
\hline
\end{tabular}

Table 6 Selected genus/species

\begin{tabular}{|c|c|c|}
\hline Top BLAST hits & Read counts & Percentage $(\%)$ \\
\hline Uncultured bacterium & 49712 & 83.52 \\
\hline Bacterium enrichment & 2543 & 4.32 \\
\hline Uncultured compost & 955 & 1.62 \\
\hline Uncultured clostridium & 947 & 1.61 \\
\hline Enterobacter cloacae & 388 & 0.66 \\
\hline Uncultured synergistetes & 355 & 0.60 \\
\hline Uncultured firmicutes & 355 & 0.60 \\
\hline Iron-reducing bacterium & 83 & 0.14 \\
\hline Uncultured Bacteroidetes & 83 & 0.14 \\
\hline Clostridium species & 59 & 0.10 \\
\hline Uncultured chloroflexi & 58 & 0.10 \\
\hline Listeria innocua & 51 & 0.09 \\
\hline Uncultured clostriaceae & 51 & 0.09 \\
\hline Uncultured rumen $s p$ & 27 & 0.05 \\
\hline Bacillus sp. & 27 & 0.05 \\
\hline Uncultured syntrophomonas & 24 & 0.04 \\
\hline Uncultured anaerobic $s p$ & 20 & 0.03 \\
\hline Clostridium pasterianum & 20 & 0.03 \\
\hline Uncultured eubacterium & 15 & 0.03 \\
\hline Uncultured ruminococcaceae & 12 & 0.02 \\
\hline Uncultured ruminococcaceae & 12 & 0.02 \\
\hline Lactobacillus fermentum & 10 & 0.02 \\
\hline Uncultured acetobacter & 5 & 0.01 \\
\hline Paracoccus denitrificans & 5 & 0.01 \\
\hline Uncultured thermomonas & 5 & 0.01 \\
\hline Enterobacter sp. & 3 & 0.01 \\
\hline Uncultured thermoanaerobacteriales & 3 & 0.01 \\
\hline Uncultured alpha & 3 & 0.01 \\
\hline Methanoculleus marisnigri & 3 & 0.01 \\
\hline Anaeromyxobacter dehalogenans & 3 & 0.01 \\
\hline Maricaulis maris & 3 & 0.01 \\
\hline Methanoculleus bourgensis & 2 & 0.00 \\
\hline Uncultured bacteroides & 2 & 0.00 \\
\hline Propionibacterium acnes & 2 & 0.00 \\
\hline Uncultured synergistaceae & 1 & 0.00 \\
\hline Ethylobacteriumpopuli & 1 & 0.00 \\
\hline Ruminococcaceae bacterium & 1 & 0.00 \\
\hline Marinobacter hydrocarbonlasticus & 1 & 0.00 \\
\hline Bifidobacterium bifidum & 1 & 0.00 \\
\hline Methanothermobacter sp. & 1 & 0.00 \\
\hline Clostridiaceae bacterium & 1 & 0.00 \\
\hline Leuconostoc pseudomesenteroides & 1 & 0.00 \\
\hline Clostridium autoethanogenum & 1 & 0.00 \\
\hline Methylobacterium platani & 1 & 0.00 \\
\hline Methylobacterium nodulans & 1 & 0.00 \\
\hline
\end{tabular}

\section{DISCUSSION}

Citrullus lanatus waste is usually composed of the entire spoiled fruits or the seeds and the edible pulp. Studies indicate that the seeds, whole fruits and rind contains mineral, proximate nutrients such as proteins, fat, moisture, fiber and higher amounts of carbohydrate (Fila et al., 2013; Tabiri et al., 2016; Olayinka and Etejere, 2018). These nutrients provide an enabling environment for the growth of microorganisms. This has made fruit waste an attractive substrate for anaerobic digestion (AD). In anaerobic digestion, microorganisms function synergistically to achieve high biogas output (Asikong et al., 2014). The microbial diversity in a biogas digester is enormous and rarely captured with cultural techniques.

In this study, the structural composition of anaerobic digester utilizing water melon (Citrullus lanatus) fruit waste was evaluated. The study revealed the 
dominant phyla to include: unknown (53739 read counts), Firmicutes (2206), Proteobacteria (1177 read counts), Planctomycetes (186 read counts), Bacteroidetes (116 read counts), Actinobacteria (84 read counts), Euryarchaeota (79 read counts) and Chloroflexi (59 read counts). The results of microbia composition of the anaerobic digester studied indicate that the digesting slurry of Citrullus lanatus waste had unique taxonomic groups and overlapping taxa with other substrate types described previously. The kingdoms taxa identified were predominantly bacteria followed by archae. This confirms the fact that bacteria and archae are the main players in anaerobic digesters.

Li et al (2015) detected firmicutes, Bacteroidetes, Proteobacteria, Chloroflexi, Synergistetes, Verrumicrobia, Spirochaetes, Actinobacteria, Tenericutes, Acidobacteria and Planctomycetes as their unique phyla using different anima manures as substrates. Compared to our finding, Tenericutes, Verrumicrobia, Spirochaetes and Acidobacteria were not found. Studies have shown that Tenericutes and Spirochaetes are obligate intracellular parasites (Ludwig $\boldsymbol{e t}$ al. 2010; Gupta et al., 2013) while Verrumicrobia and Acidobacteria are common to soil (Navarrete et al., 2015; Kielak, et al., 2016). Furthermore, Deinococcusthermus and Cyanobacteria amongst others were unique to our sample even though they have been implicated in earlier studies (Vincent et al, 2018; Detman et al., 2018).

Using metagenomics, a number of taxa have been identified in $\mathrm{AD}$ utilizing various operating conditions. These include archae such as Methanomicrobia, Methanobacteria, Methanosarcinaceae, Methanobacteriacea, Methanomicrobiales, and Methanosarcina. Dominant bacterial taxa include Clostridia, Bacilli, Bacteroidetes, Chloroflexi, Proteobacteria, Actinobacteria, Synergistetes and Thermotoga (Kleinsteuber, 2018). These taxa and archae were also detected in our study.

It was observed in this study that Firmicutes, Proteobacteria, Actinobacteria Bacteriodetes and Chloroflexi in descending order of abundance were the top five phyla present in our studied anaerobic digester. This agrees with the work of Kirkegaard et al (2017) who also reported these phyla. Among the phyla, Firmicutes was the most dominant after the Unknown phylum. The class Clostridia was the predominant of the bacterial classes in our digester. This class have been reported by Kirkegaard $\boldsymbol{e t}$ al (2017) and Jha $\boldsymbol{e t}$ al. (2012) to be active bio-degraders of a wide assortment of organic polymers.

In an earlier study, unique operational taxonomic units (OTU) were observed for different substrates even though some phyla did overlap (Li et al., 2015). In swine abundant manure sludge sample, Syntrophomonadaceae, Lachnospiraceae, Clostridiales, Clostridium XI, and Bacteria were unique OTU. In cattle abundan sample, Sporobacter, Corynebacterineae, Bacteria, Planococcaceae, Firmicutes, Clostridium sensustricto, Bacteria, Anaerovorax and Ruminococcaceae were unique. These taxonomic groups were also detected in our sample especially the Firmicutes.

In a study utilizing cow dung and straw as substrates, some of the reported dominant bacterial classes were Bacilli, Clostridia, Alphaproteobacteria and Actinobacteria (Sun et al., 2015). Compared to our study, all these bacterial classes were also reported but Clostridia had the highest reads followed by Gammaproteobacteria, Bacilli, Planctomycetes, Alphaproteobacteria, Actinobacteria and Bacteroidetes. Liu et al (2018) reported Syntrophomonas, Clostridium, Lactobacillus, and Pseudomonas as relative abundant in AD and these also detected in our samples.

Microbial community within a digester have been grouped into acidogens, syntropic acetogens and methanogens (Manyi-Loh et al., 2013). The acidogens are well known for hydrolysis ability and are often referred to as fermentative bacteria. Reported acidogens in AD include members of the family Enterobacteriaceae which in our study was the third most abundant family. Clostridium, Bacteroides, Succinivibrio, Prevotella and Ruminococcus have also been described as an important genera in the hydrolysis extensively in ruminants and biogas digesters. In our study, the abundance of these genuses Clostridium, Uncultured rumen bacteria, Bacteroidetes, and Prevotella confirms their hydrolytic roles in our cellulose rich substrate (Dowd et al., 2008; Callaway et al., 2010).

The syntrophic acetogens are usually responsible for the syntrophic metabolisms of C3 to C6 short chain fatty acids, alcohols, and amino acids (McInerney et al. 2008). This ability is almost limited to Syntrophobacter and Syntrophomonas species. In our sample, uncultured Syntrophomonas was detected. Others groups capable of this metabolism include the thermophilic bacteria (Manyi-Loh et al., 2013). These were found amongst our detected genera including the Methanothermobacter sp.

Among the archae, the genus Methanoculleusis predominant in anaerobic reactors previously studied digesters (Krober et al., 2009; Feng et al., 2010; Jaenicke et al., 2011; Jha et al., 2012). This genus was also detected in our study and the two representatives were Methanoculleus bourgensis and Methanoculleus marisnigri, with the former being more predominant member. This may be because $M$. bourgensis have been reported by Weiss et al (2009) to easily adjust to unfavorable conditions that typically inhibit the success of an anaerobic digestion operation. The important archaeal community responsible for methane gas production, at the class level were dominated by Methanomicrobia and Methanobacteria. In addition to Methanoculleus, Methanothermobacter was also detected in our sample.
Using cultural techniques to characterize microbial community in an anaerobic digester failed to reveal important member of significant phyla Firmicutes such as Clostridium species and other species that are largely unculturable due to their anaerobic requirement (Ofoefule et al., 2010; Asikong et al., 2016).

\section{CONCLUSION}

The result indicates that bacteria and archae dominated the microbial kingdoms in our anaerobic digester utilizing Citrullus lanatus fruit waste. Dominant phyla were Unknown, Firmicutes, Proteobacteria, Planctomycetes, Bacteroidetes, Actinobacteria and Euryarchaeota in decreasing order of counts. As expected, classes, orders, families belonging to these top phyla dominated the class, order and family classifications. A total of 210 phylotypes were obtained out of which half of these were not routinely culturable isolates. These findings confirm the fact that $\mathrm{AD}$ systems harbor complex microbial communities that are unculturable using routine media. Interestingly, phylotypes involved in key processes of $\mathrm{AD}$ such as hydrolysis, acidogenesis, acetogenesis, acetogenesis and methanogenesis were obtained indicating a self-sustaining and synergistic AD.

Conflict of interest: The authors hereby declare that no conflict of interest exist.

\section{REFERENCES}

Amha, Y. M., Anwar, M. Z., Brower, A., Jacobsen, C. S., Stadler, L. B., Webster T. M., \& Adam, L. S. (2018). Inhibition of anaerobic digestion processes: applications of molecular tools. Bioresource Technology, 247, 999-1014. http://dx.doi.org/10.1016/j.biortech.2017.08.210.

Anika, O. C., Akin-Osanaiye, B. C., Asikong, E. B., \& Edet, U. O. (2019). The potential of biogas production from fruit wastes (Watermelon, Mango and Pawpaw). World Journal of Advanced Research and Reviews, 1(3), 52-65. http://dx.doi.org/10.30574/wjarr.2019.1.3.0026.

Asikong, B., Udensi, O., Epoke, J., Eja, M., \& Antai, E. (2014). Microbial analysis and biogas yield of water hyacinth, cow dung digesters. British Journal of Applied Science and Technology, 4(4), 650-661. http://dx.doi.org/10.9734/bjast/2014/5662

Asikong, B., Idire, S. O., \& Tiku, D. R. (2014). Microorganisms associated with biogas production using vegetable (Telfairia occidentalis) wastes, Banana pee and pig dung as substrates. British Microbiology Research Journal, 16(3), 1-12. http://dx.doi.org/10.9734/BMRJ/2016/28294.

Callaway, T. R., Dowd, S.E., Edrington, T.S., Anderson, R.C., Krueger, N., Bauer, N., Kononoff, P., \& Nisbet, D. J. (2010) Evaluation of bacterial diversity in the rumen and feces of cattle fed different levels of dried distillers grains plus solubles using bacterial tagencoded FLX amplicon pyrosequencing. Journal of Animal Science, 88, 3977-3983. http://dx.doi.org/10.2527/jas.2010-2900.

Cirine, D., Lentomaki, A., \& Blackhall, L. (2007). Hydrolysis and microbial community analysis in two stage anaerobic digestion of energy crops. Journal of Applied Microbiology, 103, 576-527. http://dx.doi.org/10.1111/j.13652672.2006.03270.

Bjornsson, L. (2001). Evaluation of new methods for the monitoring of alkalinity, dissolved hydrogen and the microbial community in anaerobic digestion. Water Research Journal, 35(12), 2833-2840. http://dx.doi.org/10.1016/S00431354(00)00585-6.

Detman, A., Mielecki, D., Piesniak, L., Bucha, M., Janiaga, M., Matyasik, I., Chojnacka, A., Jedrysek, M. O., Blaszczyk, M. K., \& Sikora, A. (2018). Methane-yielding microbial communities processing lactate-rich substrates: a piece of the anaerobic digestion puzzle. Biotechnology for Biofuels, 11, 116-134. http://dx.doi.org/10.1186/s13068-018-1106-z.

Ding, S., Crowley, M., \& Hummel, E. (2008). A biophysical perspective on cellulosome. New Perspective for Biomass conversion. Current Opinion in Biotechnology, 19, 218-227. http://dx.doi.org/10.1016/j.copbio.2008.04.008.

Doi, R. (2008). Cellulases of mesophilic microorganisms. Annual New York $\begin{array}{llrr}\text { Academy } & \text { of } & \text { Science, } & 1125,\end{array}$ http://dx.doi.org/10.1016/j.copbio.2008.04.008.

Dowd, S., Callaway, T., Wolcott, R., Sun, Y., McKeehan, T., Hagevoort, R., \& Edrington, T. (2008) Evaluation of the bacterial diversity in the feces of cattle using 16S Rdna bacterial tag-encoded FLX amplicon pyrosequencing (bTEFAP). BMC Microbiology, 8, 125. http://dx.doi.org/10.1186/1471-2180- 8-125.

Edet, U. O., Antai, S. P., Brooks, A. A., \& Asitok, A. D. (2017). An overview of cultural, molecular and metagenomics techniques in description of microbial diversity. Journal of Advances in Microbiology, 7(2), 1-19. http://dx.doi.org/10.9734/JAMB/2017/37951.

Edet, U. O., Antai, S. P., Brooks, A. A., \& Asitok, A. D. (2017). Metagenomic Assessment of Antibiotics Resistance Genes from Four Ecosystems in the Niger Delta Area of Nigeria. Asian Journal of Biotechnology and Genetic Engineering, 1(1), 1-10. http://dx.doi.org/10.9734/AJBGE/2017/38009.

Edet, U. O., Antai, S. P., Brooks, A. A., \& Asitok, A. D. (2018). Microbiological examination and physicochemical analysis of estuary water used as point of source drinking water. International Journal of pathogen research, 1(1), 1-13. http://dx.doi.org/10.9734/IJPR/2018/41432. 
Edet, U. O., Antai, S. P., Brooks, A. A., \& Asitok, A. D. (2018). Evaluation of microbial diversity of epipellic and benthic sediment using cultural and metagenomics techniques. Asian Journal of Environment \& Ecology. 6 (4), 1-13. http://dx.doi.org/10.9734/AJEE/2018/41431.

Feng, X. M., Karlsson, A., \& Svensson, B. H. (2010). Impact of trace element addition on biogas production from food industrial waste - linking process to microbial communities. FEMS Microbial Ecology, 74, 226-240. http://dx.doi.org/10.1111/j.1574-6941.2010.00932.x.

Fila, W. A., Itam, E. H., Johnson, J. T., Odey, M. O., Effiong, E. E., Dasofunjo, K., \& Ambo, E. E. (2013). Comparative Proximate Compositions of Watermelon Citrullus Lanatus, Squash Cucurbita Pepo'land Rambutan Nephelium Lappaceum. International Journal of Science and Technology, 2(10), 81-88.

Gupta, R. S., Mahmood, S., \& Adeolu, M. (2013). A phylogenomic and molecular signature based approach for characterization of the phylum Spirochaetes and its major clades: proposal for a taxonomic revision of the phylum. Frontiers in Microbiology, 4, 217-220. http://dx.doi.org/10.3389/fmicb.2013.00322.

Ijah, U. J. J., Ayodele, H. S., \& Aransiola, S. A. (2015). Microbiological and Some Sensory Attributes of Water Melon Juice and Watermelon-orange Juice Mix. Journal of Food Resource Science 4 (3), 49-61. http://dx.doi.org/10.3923/ifrs.2015.49.61.

Jaenicke, S. Ander, C., Bekel, T., Bisdorf, R., Droge, M., Gartemann, K., Junemann, S. Kaiser, O., Krause, L., Tille, F., Zakrzewski, M., Puhler, A., Schluler, A., \& Goesmann, A. (2011). Comparative and joint analysis of two metagenomic data sets from a biogas fermenter obtained by 454 -pyrosequencing. Public Library of Science Journal, 6(1), 4519-4534. http://dx.doi.org/10.1371/journal.pone.0014519.

Jha, A. K., Li, J. Ban, Q., Zang, L., \& Zhoa, B. (2012). Dry anaerobic digestion of cow dung for methane production: Effect of mixing. Pakistan Journal of Biosciences, 15(23), 1111-1118. http://dx.doi.org/10.3923/pjbs.2012.1111.1118. Kielak, A. M., Barreto, C. C., Kowalchuk, G. A., van Veen, J. A. \& Kuramae, E. E. (2016). The Ecology of Acidobacteria: Moving beyond Genes and Genomes

\section{Frontiers in Microbiology, 7, 744-760.} http://dx.doi.org/10.3389/fmicb.2016.00744

Kirkegaard, R. H., Mcllroy, S. J., Kirstensen, J. M., Nierychlo, M., Karst, S. M. Dueholmam, M. S., Albertsen, M., \& Neilsen, P. H. (2017). The impact of immigration on community composition in full scale anaerobic digesters. Journal of Scientific Reports, 7, 9343-9354. http://dx.doi.org/10.1038/s41598-01709303-0.

Kleinsteuber, S. (2018). Metagenomics of Methanogenic Communities in Anaerobic Digesters. Stams, A. J. M., \& Sousa, D. Z. (eds.), Biogenesis of Hydrocarbons, Handbook of Hydrocarbon and Lipid Microbiology, pp. 1-23 http://dx.doi.org/10.1007/978-3-319-53114-4 16-1.

Krober, M., Bekel, T., Diaz, N. N., Goesmann, A., Jaenicke, S., Krause, L. Miller, D., Runte, K. J., Viehover, P., Puhler, A., \& Schluter, A. (2009). Phylogenetic characterization of a biogas plant microbial community integrating clone library 16s-rDNA sequences and metagenome sequence data obtained by 454-pyrosequencing. Journal of Biotechnology, 42(1), 38-49. http://dx.doi.org/10.1016/j.jbiotec.2009.02.010.

Li, J., Rui, J., Yao, M., Zhang, S., Yan, X., Wang, Y., Yan, Z., \& Li, X. (2015) Substrate Type and Free Ammonia Determine Bacterial Community Structure in Full-Scale Mesophilic Anaerobic Digesters Treating Cattle or Swine Manure Frontiers in Microbiology, 6:1337. http://dx.doi.org/10.3389/fmicb.2015.01337.

Lin, L., Wan, C., Liu, X., Lee, D. J., Lei, Z., Zhang, Y., \& Tay, J. H. (2013) Effect of initial $\mathrm{pH}$ on mesophilic hydrolysis and acidification of swine manure. Bioresource Technology 136

302-308.

http://dx.doi.org/10.1016/j.biortech.2013.02.106

Liu, T., Sun, L., Norderg, A., \& Schnurer, A. (2018). Substrate-Induced Response in Biogas Process Performance and Microbial Community Relates Back to Inoculum Source. Microorganisms, 6, 80-99. http://dx.doi.org/10.3390/microorganisms6030080.

Ludwig W., Euzéby J., \& Whitman W.B. (2010) Taxonomic outlines of the phyla Bacteroidetes, Spirochaetes, Tenericutes (Mollicutes), Acidobacteria, Fibrobacteres, Fusobacteria, Dictyoglomi, Gemmatimonadetes, Lentisphaerae, Verrucomicrobia, Chlamydiae, and Planctomycetes. In: Krieg N.R. et al. (eds) Bergey’s Manual ${ }^{\circledR}$ of Systematic Bacteriology. Springer, New York, NY, pp. 21 24 http://dx.doi.org/10.1007/978-0-387-68572-4_2.

Manyi-Loh, C. E., Mamphweli, S. N., Meyer, E. L., Okoh, A. I., Makaka, G., \& Simon, M. (2013). Microbial Anaerobic Digestion (Bio-Digesters) as an Approach to the Decontamination of Animal Wastes in Pollution Control and the Generation of Renewable Energy. International Journal of Environmental Research Public Health, 10, 4390-4417. http://dx.doi.org/10.3390/ijerph10094390.

Manyi-Loh, A., \& Parawira, W. (2009). Biogas technology research in selected sub-Saharan African countries. African Journal of Biotechnology, 8, 116-125.

Mclnerney, M. J., Struchtemeyer, C. G., Sieber, J., Mouttaki, H. Stams, A. J., Schink, B.. Rohlin, L., \& Gunsalus, R. P. (2008). Physiology, Ecology, Phylogeny, and Genomics of Microorganisms Capable of Syntrophic
Metabolism. Annals of the New York Academy of Sciences, 1125(1), 58-72. http://dx.doi:10.1196/annals.1419.005.

Mori, K., \& Kagamata, Y. (2014). The Challenges of Studying the Anaerobic $\begin{array}{lllll}\text { Microbial World. Microbes Environ. } 29 & \text { (4), 335-337. }\end{array}$ http://dx.doi.org/10.1264/jsme2.ME2904rh.

Navarrete, A. A., Soares, T., Rossetto, R., van Veen, J. A., Tsai, S. M., \& Kuramea, E. E. (2015). Verrucomicrobial community structure and abundance as indicators for changes in chemical factors linked to soil fertility. Antonie Van Leeuwenhoek, 108(3), 741-752. http://dx.doi:10.1007/s10482-0150530-3

Nelson, M.C., Morrison, M., \& Yu, Z. (2010). A meta-analysis of the microbia diversity observed in anaerobic digesters. Bioresource Technology, 102, 3730 3739. http://dx.doi.org/10.1016/j.biortech.2010.11.119.

Ofoefule, A.U., Uzodinma, E.O., \& Anyanwu, C.N. (2010). Studies on the Effect of Anaerobic Digestion on the Microbial Flora of Animal Wastes 2: Digestion and Modelling of Process Parameters. Trends in Applied Sciences Research, 5, 39-47. http://dx.doi.org/10.3923/tasr.2010.39.47.

Oladepo, O. W., Ilori, M. O., \& Taiwo, K. A. (2015). Assessment of the waste generation and management practices in Nigerian food industry: towards a policy for sustainable approaches. American Journal of Scientific and Industrial Research, 6(1), 12-22. http://dx.doi.org/10.5251/ajsir.2015.6.1.12.22.

Olayinka, B. U. \& Etejere, E. O. (2018). Proximate and Chemical Composition of Watermelon (Citrullus lanatus (Thunb.)) Matsum and Nakai cv red and cucumber (Cucumis sativus L. cv Pipino). International Food Research Journal, 25(3), 1060-1066

Parawira, W. (2005). Profile of hydrolases and biogas production during twostage mesophilic anaerobic digestion of solid potato waste. Journal of Biochemistry, 40(9), 25-29. http://dx.doi:10.1016/j.procbio.2005.01.010.

Sagagi, B., Garba, B., \& Usman, N. (2009). Studies on biogas production from fruits and vegetable wastes. Bayero Journal of Pure and Applied Science, 2, 115 118. http://dx.doi:10.4314/bajopas.v2i1.58513

Sagar, N. A., Pareek, S., Sharma, S., Yahia, E. M., \& Lobo, M G. (2018). Fruit and Vegetable Waste: Bioactive Compounds, Their Extraction, and Possible Utilization. Comprehensive Reviews in Foods and Food Safety, 17, 512-531. http://dx.doi.org/10.1111/1541-4337.12330.

Salam, L. B., Obayori, S. O., Nwaokorie, F. O., Suleiman, A., \& Mustapha, R (2017). Metagenomic insights into effects of spent engine oilperturbation on the microbial community composition and function in a tropical agricultural soil Environmental Science Pollution Resource. http://dx.doi.org/10.1007/s11356017-8364-3.

Schink, B. (1997). Energetic of dystrophic cooperation in methanogenic degradation. Microbial Molecular Biology Revolution, 61, 262-280.

Sun, L, Pope, P. ., Eijsink, V. G. H., \& Schnürer, A. (2015). Characterization of microbial community structure during continuous anaerobic digestion of straw and cow manure. Microbial biotechnology. Microbial Biotechnology, 8(5), 815827. http://dx.doi.org/10.1111/1751-7915.12298

Tabiri, B., Agbenorhevi, J. K., Wireko-Manu, F. D., \& Ompouma, E. I. (2016). Watermelon Seeds as Food: Nutrient Composition, Phytochemicals and Antioxidant Activity. International Journal of Nutrition and Food Sciences, 5(2), 139-144. http://dx.doi.org/10.11648/i.ijnfs.20160502.18

Town, J. R., Links, M. G., Fonstad, T. A., \& Dumonceaux, T. J. (2014) Molecular characterization of anaerobic digester microbial communities identifies microorganisms that correlate to reactor performance. Bioresource Technology, 151, 249-257. http://dx.doi.org/10.1016/j.biortech.2013.10.070.

Verma, V., Singh, Y., \& Rai, J. (2007). Biogas production from plant biomass used for phytoremediation of industrial wastes. Bioresource Technology, 98 1664-1669. http://dx.doi.org/10.1016/j.biortech.2006.05.038.

Vincent, N. M., Wei, Y., Zhang, J., Yu, D., \& Tong, J. (2018). Characterization and Dynamic Shift of Microbial Communities during Start-Up, Overloading and Steady-State in an Anaerobic Membrane Bioreactor. Int. J. Environ. Res. Public Health 2018, 15, 1399; http://dx.doi:10.3390/ijerph150713999.

Weiss, A., Jerome, V., \& Burghardt, D. (2009). Investigation of factor influencing biogas production in a large scale thermophillic municipal biogas plant. Applied Microbiology and Biotechnology Journal, 84, 987-1001. http://dxdoi.org/10.1007/s00253-009-2093-6. Epub 2009 Jul 14.

Zhang, W., Werner, J. J., Agler, M. T. and Angenent, L. T. (2014).Substrate type drives variation in reactor microbiomes of anaerobic digesters. Bioresource Technology, 151, 397-401. http://dx.doi.org/10.1016/j.biortech.2013.10.004. 